Article

\title{
Chromium(III) Removal from Wastewater by Chitosan Flakes
}

\author{
Loris Pietrelli ${ }^{1,2, *}$, Iolanda Francolini ${ }^{2} \oplus$, Antonella Piozzi ${ }^{2} \oplus$, Maria Sighicelli ${ }^{1}$, \\ Ilaria Silvestro ${ }^{2}$ and Marco Vocciante ${ }^{3}$ DD \\ 1 ENEA, CR Casaccia, Via Anguillarese 301, 00060 Roma, Italy; maria.sighicelli@enea.it \\ 2 Dipartimento di Chimica, Università di Roma Sapienza, 00185 Roma, Italy; \\ iolanda.francolini@uniroma1.it (I.F.); antonella.piozzi@uniroma1.it (A.P.); ilaria.silvestro@uniroma1.it (I.S.) \\ 3 Dipartimento di Chimica e Chimica Industriale, Università degli Studi di Genova, Via Dodecaneso 31, \\ 16146 Genova, Italy; marco.vocciante@unige.it \\ * Correspondence: loris.pietrelli@uniroma1.it
}

Received: 30 January 2020; Accepted: 7 March 2020; Published: 11 March 2020

check for updates

Featured Application: The ability of chitosan as a low-cost and environmentally friendly $\mathrm{Cr}$ (III) adsorbent was studied to evaluate its potential application in the field of tannery wastewater treatment, in terms of the removal of chromium ions avoiding their conversion into $\mathrm{Cr}(\mathrm{VI})$, the compounds of which exert highly toxic and carcinogenic effects on biological systems.

\begin{abstract}
Chitosan is very effective in removing metal ions through their adsorption. A preliminary investigation of the adsorption of chromium(III) by chitosan was carried out by means of batch tests as a function of contact time, $\mathrm{pH}$, ion competition, and initial chromium(III) concentration. The rate of adsorption was rather rapid $\left(\mathrm{t}_{1 / 2}<18 \mathrm{~min}\right)$ and influenced by the presence of other metal ions. The obtained data were tested using the Langmuir and Freundlich isotherm models and, based on $\mathrm{R}^{2}$ values, the former appeared better applicable than the latter. Chitosan was found to have an excellent loading capacity for chromium(III), namely $138.0 \mathrm{mg} \mathrm{Cr}$ per g of chitosan at $\mathrm{pH}=3.8$, but metal ions adsorption was strongly influenced by the $\mathrm{pH}$. About $76 \%$ of the recovered chromium was then removed simply by washing the used chitosan with $0.1 \mathrm{M}$ EDTA (Ethylenediaminetetraacetic acid) solution. This study demonstrates that chitosan has the potential to become an effective and low-cost agent for wastewater treatment (e.g., tannery waste) and in situ environmental remediation.
\end{abstract}

Keywords: chitosan; chromium; heavy metals; adsorption; kinetics; low-cost adsorbent; tannery; ion exchange

\section{Introduction}

The removal of heavy metal ions from aqueous solutions, both for pollution control and for the recovery of raw materials, has assumed increasing importance in recent years. Among the many metals potentially harmful to the environment and human health, chromium pollution is of considerable concern, as the metal is widely used in many industrial activities such as electroplating, leather tanning, nuclear power plants, and textile industries [1,2].

To address this problem, numerous separation techniques are currently available (e.g., adsorption, ion exchange, selective precipitation, nanofiltration, etc.), the selection of which, however, is far from trivial and deserves extensive attention to avoid a suboptimal choice or the failure of the reclamation activity [3]. In general, adsorption-based technologies have proven to be among the most viable alternatives proposed for the treatment of industrial wastewater contaminated by a wide variety of pollutants, both organic [4] and inorganic $[5,6]$, due to the low processing and 
instrumentation costs, the simplicity of operation, and the availability of different types of low-cost and environmentally friendly adsorbents. A wide range of materials, including activated carbon [7], metal oxides, carbon nanotubes, polymers, agricultural residues [8], and natural and modified clays [9], have been used successfully to adsorb heavy metals from aqueous solutions. This is even more interesting when it is possible to exploit low-cost adsorbent materials from industrial waste [10], with a double advantage for the environment, in line with operational guidelines such as the Circular Economy and the "near-zero discharge" of hazardous waste [11] established by the most recent European laws.

In this context, a very promising and inexpensive material is chitosan (poly- $\beta$-(1 $\rightarrow 4)$-2-amino-2-deoxy-D-glucose), a nitrogenous polysaccharide prepared from chitin by partially deacetylating its acetoamine groups using strong alkaline solutions at about $70{ }^{\circ} \mathrm{C}$. Chitosan has a high potential for the adsorption of metal ions, since it has both amino and hydroxyl groups that can act as chelation sites for metal ions. One of the most interesting advantages of chitosan is its versatility, since the material can be easily physically modified to obtain different forms of polymers such as beads [12], membranes [13], or sponges [14] for different applications. Chitosan can also be easily chemically modified to increase its applications [15]. Recently, several critical reviews have been published on the many applications of chitosan as an environmentally friendly biomaterial [16], ranging from the medical field [17] to food technology [18] and environmental protection [19].

Chromium can be found in the environment in the forms $\mathrm{Cr}(\mathrm{III})$ and $\mathrm{Cr}(\mathrm{VI})$, as its other oxidation states are not stable in aerated aqueous media [20]. The trivalent state is the most stable form in reducing conditions and is present as a cationic species $\left(\mathrm{Cr}(\mathrm{OH})^{2+}, \mathrm{Cr}(\mathrm{OH})_{2}^{+}\right)$, with the first or second hydrolysis products dominating at $\mathrm{pH}$ values from 4 to 8 . The low solubility of $\mathrm{Cr}(\mathrm{OH})_{3}(\log \mathrm{k}=$ -16.19) considerably limits the concentration of $\mathrm{Cr}(\mathrm{III})$ for $\mathrm{pH}$ values above about 5 .

Given its high danger to biological systems, many studies have focused on the removal of $\mathrm{Cr}(\mathrm{VI})$, while very few articles deal with the adsorption of $\mathrm{Cr}$ (III) by chitosan. Maruca et al. [21] reported the uptake of $\mathrm{Cr}$ (III) ions by chitosan flakes and the effect of $\mathrm{PO}_{4}{ }^{3-}$ on the adsorption mechanism. Chui and collaborators [22] studied the removal of $\mathrm{Cr}$ (III) using a packed column filled with crab chitosan. More recently, Singh \& Nagendran [23] reported comparative studies on the sorption of $\mathrm{Cr}$ (III) on chitin and chitosan in terms of a comparison between Langmuir and Freundlich isotherms. Overall, the papers often concern the application of chitosan membranes or beads, and not of chitosan flakes.

Considering that equilibrium analysis is the most important fundamental study required to evaluate the affinity of a sorbent, the ability of chitosan to remove chromium(III) by adsorption was studied in the present work to evaluate its potential application in the field of tannery wastewater treatment [1]. Numerous adsorption tests of chromium(III) on chitosan flakes were conducted to investigate the effects of contact time, $\mathrm{pH}$, initial $\mathrm{Cr}(\mathrm{III})$ concentration, and, using real wastewater, ion competition. The thermodynamic behavior was assessed using the well-known Langmuir and Freundlich isotherm models.

\section{Materials and Methods}

\subsection{Material and Reagents}

Chitosan (molecular weight: $400 \mathrm{k}, 66.9 \%<40$ mesh, degree of deacetylation: $84-86 \%$ ) was provided by Merck KGaA (Darmstadt, Germany) and used without further purification. Its surface area, estimated with the nitrogen adsorption method (BET, Quantachrome Nova 2200, Quantachrome Instruments, Boynton Beach, FL, U.S.), was equal to $1.578 \mathrm{~m}^{2} \mathrm{~g}^{-1}$. The water content of this commercial chitosan, determined by thermogravimetric analysis (TGA1, Mettler Toledo, OH, U.S.), was 12.7\%, while its decomposition temperature was $292.12{ }^{\circ} \mathrm{C}$ (Figure 1). In order to study the effect of particle size on the adsorption of metal ions, two granulometric fractions $(<0.42 \mathrm{~mm}$ and $>0.42 \mathrm{~mm}$ ) were obtained from the starting material by using a sieve shaker. Analytical grade chemicals were supplied by Merck Co. (Kenilworth, NJ, U.S.); aqueous solutions were prepared dissolving $\mathrm{Cr}\left(\mathrm{NO}_{3}\right)_{3}$ at different 
concentrations in deionized water (Millipore Milli-Q, Merck KGaA, Darmstadt, Germany), and the initial $\mathrm{pH}$ was adjusted by adding a few drops of $\mathrm{HNO}_{3}$ and $\mathrm{NaOH}$ solutions.

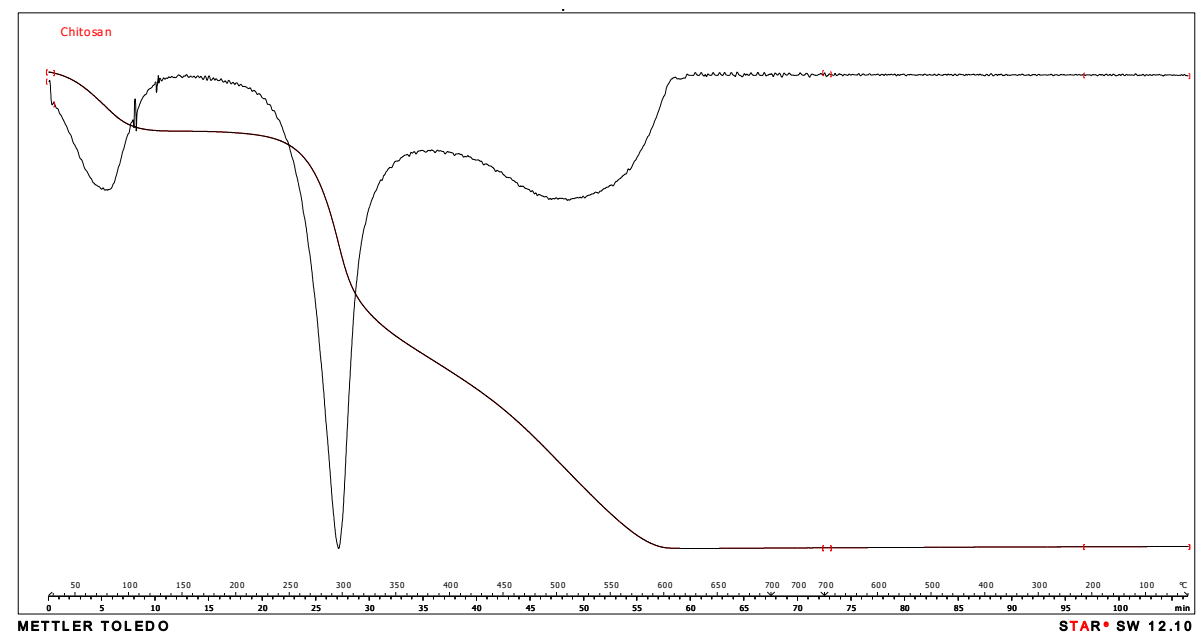

Figure 1. Thermogravimetric analysis (TGA) of the chitosan sample.

\subsection{Adsorption Tests}

Batch experiments (in triplicate) were carried out using 100 and $500 \mathrm{mg}$ of adsorbent each time; chitosan was added to $50 \mathrm{~mL}$ of $\mathrm{Cr}$ solution in a conical flask. The stirring rate was set at $120 \mathrm{rpm}$ for all adsorption/desorption tests using a temperature-controlled magnetic stirrer. Analysis of metal ions was carried out using an ICP-optical emission spectrometer (Inductively Coupled Plasma, Optima 2000 DV, Perkin Elmer, Waltham, MA, U.S.).

For experiments on the $\mathrm{pH}$ effect, the solutions were initially adjusted with aqueous solutions of acid or base $\left(0.01 \mathrm{M} \mathrm{HNO}_{3}\right.$ and/or $\left.0.01 \mathrm{M} \mathrm{NaOH}\right)$ to reach $\mathrm{pH}$ values between 0.5 and 5 , and thus avoid the precipitation of $\mathrm{Cr}(\mathrm{OH})_{3}$. Isotherms were recorded during the execution of adsorption experiments with various initial metal concentrations $\left(C_{0}=50-2000 \mathrm{mg} \mathrm{L}^{-1}\right)$ at $20^{\circ} \mathrm{C}$. Kinetic tests were performed using $100 \mathrm{mg}$ of chitosan flakes, 100 and $500 \mathrm{mg} \mathrm{L}^{-1}$ as the initial metal concentration at $20^{\circ} \mathrm{C}$, and $\mathrm{pH}=3.8$ for fixed time intervals during adsorption $(\mathrm{t}=0-24 \mathrm{~h})$. The effect of the granulometry of the flakes on the adsorption capacity was investigated using the two granulometric fractions of chitosan $(<0.42 \mathrm{~mm}$ and $>0.42 \mathrm{~mm})$ under the same conditions. For all adsorption batch tests, a contact time of 120 min was set.

The equilibrium amount of metal in the solid phase, expressed as $Q_{e}\left(\mathrm{mg} \mathrm{g}^{-1}\right)$, was determined with reference to the mass balance equation: $Q_{e}=\left(C_{0}-C_{e}\right) \times(V / m)$, where $C_{0}$ and $C_{e}\left(m^{-1}\right)$ are the initial and equilibrium metal concentrations, respectively, $\mathrm{V}(\mathrm{L})$ is the volume of the aqueous solutions, and $\mathrm{m}(\mathrm{g})$ is the mass of the adsorbent.

Dynamic tests were performed using a glass column with an internal diameter of $0.9 \mathrm{~cm}$ and a bed high of $40 \mathrm{~cm}$, filled with $2 \mathrm{~g}$ of chitosan. Tests were performed using both a real wastewater solution and a $500 \mathrm{mg} \mathrm{L}^{-1}$ chromium(III) solution at $\mathrm{pH}=3.5$, imposing a flow rate of $23.6 \mathrm{~mL} \mathrm{~h}^{-1}$ $\left(1 \mathrm{BV} \mathrm{h}^{-1}\right)$ by using a peristaltic pump.

The real wastewater, a tannery washing solution, had the following composition: $\mathrm{pH}=3.2$, Chemical Oxygen Demand, COD $=9.1 \mathrm{~g} \mathrm{~L}^{-1}$, Total Suspended Solids, $\mathrm{TSS}<1 \mathrm{~g} \mathrm{~L}^{-1}, \mathrm{Cr}^{3+}=635 \mathrm{mg} \mathrm{L}^{-1}$, $\mathrm{Na}^{+}=1050 \mathrm{mg} \mathrm{L}^{-1}, \mathrm{Mg}^{2+}=760 \mathrm{mg} \mathrm{L}^{-1}, \mathrm{Ca}^{2+}=300 \mathrm{mg} \mathrm{L}^{-1}, \mathrm{Zn}^{2+}=115 \mathrm{mg} \mathrm{L}^{-1}, \mathrm{Cd}^{2+}=87 \mathrm{mg} \mathrm{L}^{-1}$, $\mathrm{SO}_{4}{ }^{2-}=1.820 \mathrm{mg} \mathrm{L}^{-1}$, and $\mathrm{Cl}^{-}=818 \mathrm{mg} \mathrm{L}^{-1}$.

Desorption experiments were performed in batch mode $\left(\mathrm{T}=20^{\circ} \mathrm{C}, \mathrm{t}=24 \mathrm{~h}\right)$. In particular, after the end of the adsorption phase, the adsorbent material was separated from the supernatant using filtration membranes $(0.22 \mu \mathrm{m})$. Then, desorption tests were performed using $50 \mathrm{~mL}$ solutions of $\mathrm{H}_{2} \mathrm{SO}_{4}$ and EDTA as desorption reagents at a concentration of $0.1 \mathrm{M}$ and $0.05 \mathrm{M}$, respectively. 
The quantitative evaluation of desorption was carried out using desorption percentages calculated from the difference between the amount of metal loaded on the adsorbent after adsorption and the amount of metal in solution after desorption. To investigate the reuse capacity of the adsorbents, the above procedure was repeated 5 times under the same conditions (first adsorption and then desorption).

\section{Results}

\subsection{Adsorption Dynamics}

The uptake of metal ions from the solution involves several steps, necessary for the transfer of the solute from the liquid phase to the specific sites within the chitosan particles (e.g., external diffusion and intraparticle diffusion).

In the case of chitosan, its chains have a large number of the $-\mathrm{NH}_{2}$ and $-\mathrm{OH}$ groups distributed throughout the structure, making the kinetic or mass transfer representation likely to be global. The $-\mathrm{NH}_{2}$ groups are the most important binding sites for metal ions [24], yet the hydroxyl groups can also contribute as coordinator groups, especially those in C-3 position [15,22]. To examine the adsorption mechanism of the metal ion of interest, two kinetic models were tested:

i. the pseudo-first-order equation described by Lagergren [25], which can be rearranged to obtain a linear form as shown by Equation (1):

$$
\log \left(q_{e}-q_{t}\right)=\log \left(q_{e}\right)-\left(k_{1} / 2.303\right) t
$$

ii. a pseudo-second-order equation based on the equilibrium adsorption capacity, which can be expressed as in Equation (2):

$$
t / q_{t}=\left(1 / k_{2} q_{e}^{2}\right)+\left(1 / q_{e}\right) t
$$

In the above equations, $q_{e}\left(\mathrm{mg} \mathrm{g}^{-1}\right)$ represents the quantity of $\mathrm{Cr}(\mathrm{III})$ adsorbed when the system is at equilibrium, $q_{t}\left(\mathrm{mg} \mathrm{g}^{-1}\right)$ is the quantity of $\mathrm{Cr}(\mathrm{III})$ adsorbed at time $t$, and $k_{1}\left(\mathrm{~min}^{-1}\right)$ and $k_{2}\left(\mathrm{~g} \mathrm{mg}^{-1}\right.$ $\mathrm{min}^{-1}$ ) are the rate constants of the pseudo-first and pseudo-second order kinetic models, respectively.

Given that Equations (1) and (2) are not able to provide information on the adsorption mechanism, the simplified intraparticle diffusion model [26] was also tested, being $k_{i}\left(\mathrm{~g} \mathrm{mg}^{-1} \mathrm{~min}^{-1}\right)$ the rate constant of the model:

$$
q_{t}=k_{i} t^{1 / 2}
$$

The validity of these models was assessed by analyzing the slopes and intercepts of $\log \left(q_{e}-q_{t}\right)$ vs. $t, t / q_{t}$ vs. $t$, and $q_{t}$ vs. $t^{1 / 2}$ for each of the linearized equations.

The results obtained with different concentrations of chromium(III) are shown in Table 1 in terms

\begin{tabular}{|c|c|c|c|c|c|c|c|}
\hline \multicolumn{3}{|c|}{ 1st Order Kinetic Model } & \multicolumn{3}{|c|}{ 2nd Order Kinetic Model } & \multicolumn{2}{|c|}{ Intraparticle Diffusion Model } \\
\hline $\begin{array}{c}k_{1} \\
\left(\mathrm{~min}^{-1}\right)\end{array}$ & $\begin{array}{c}q_{e, c a l} \\
\left(\mathrm{mg} \mathrm{g}^{-1}\right)\end{array}$ & $\mathrm{R}^{2}$ & $\begin{array}{c}k_{2} \\
\left(\mathrm{~g} \mathrm{mg}^{-1} \mathrm{~min}^{-1}\right)\end{array}$ & $\begin{array}{c}q_{e, c a l} \\
\left(\mathrm{mg} \mathrm{g}^{-1}\right)\end{array}$ & $R^{2}$ & $\begin{array}{c}k_{i} \\
\left(\mathrm{~g} \mathrm{mg}^{-1} \min ^{-1}\right)\end{array}$ & $R^{2}$ \\
\hline $1.07 \times 10^{-2}$ & 9.32 & 0.7838 & $5.07 \times 10^{-3}$ & 23.89 & 0.9987 & 1.711 & 0.9199 \\
\hline
\end{tabular}
of correlation coefficients $\left(\mathrm{R}^{2}\right)$ as well as calculated and experimental adsorption capacity values.

Table 1. Values of the adsorption kinetic constants at $\mathrm{T}=20^{\circ} \mathrm{C}, \mathrm{pH}=3.8, \mathrm{C}_{0}=0.5 \mathrm{~g} \mathrm{~L}^{-1}$.

The correlation coefficient $\mathrm{R}^{2}$ for the pseudo-second-order adsorption model was the highest and, in fact, its estimate of the equilibrium adsorption capacity $q_{e, \text { cal }}$ was quite close to the experimental $q_{t}$ values (23-28.5 $\mathrm{mg} \mathrm{g}^{-1}$ as shown in Figure 2 for the two grain-sizes). These results suggest that a second-order mechanism is predominant and that the overall $\mathrm{Cr}(\mathrm{III})$ adsorption rate is controlled by a chemisorption process. 


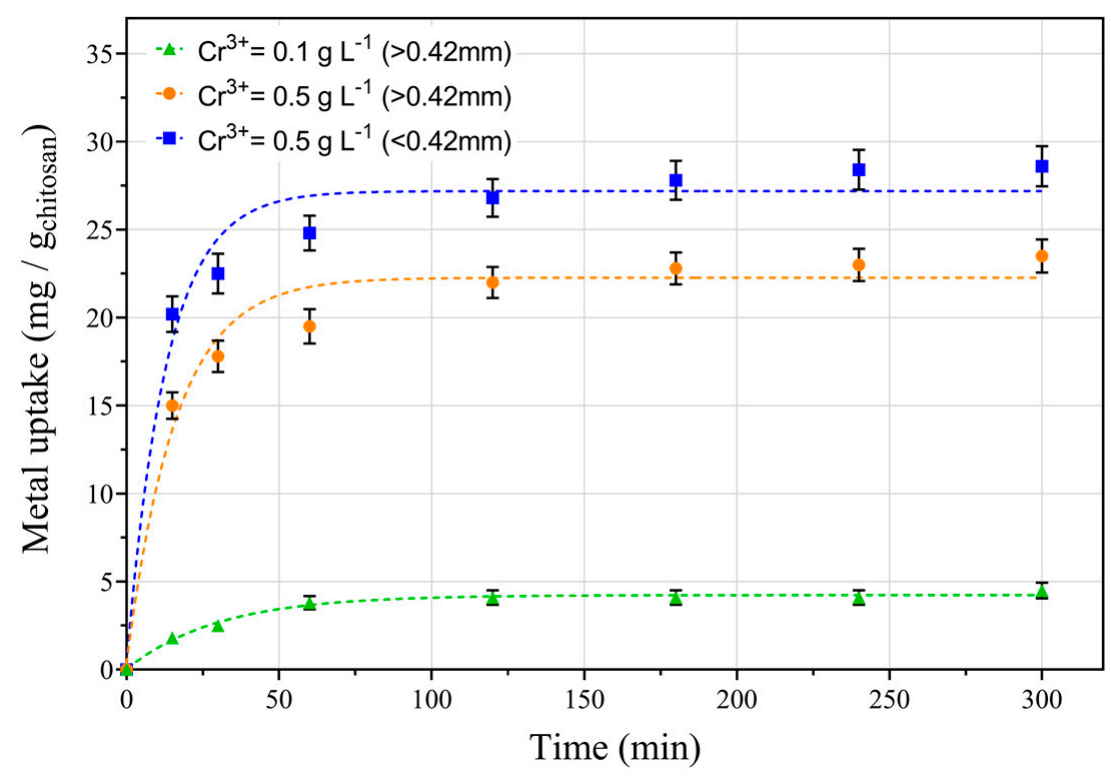

Figure 2. Effect of the grain size of the flakes on the adsorption of $\mathrm{Cr}$ (III) on chitosan (100 $\mathrm{mg}$ ), at $\mathrm{pH}=3.8, \mathrm{~T}=20^{\circ} \mathrm{C}$, and $\mathrm{C}_{0}=100$ and $500 \mathrm{mg} \mathrm{L}^{-1}$ of $\mathrm{Cr}(\mathrm{III})$.

\subsection{Grain Size Effect}

Figure 2 shows the effect of the grain size of the flakes on the adsorption capacity at $\mathrm{pH}=3.8$ and $\mathrm{T}=20^{\circ} \mathrm{C}$. It can be observed that the metal uptake was higher on particles with a small size $(<0.42 \mathrm{~mm})$. This is likely due to the higher surface area exposed by these particles, which favors the removal of $\mathrm{Cr}$ (III) from the solution in the initial stages of the adsorption process. This phenomenon, previously reported for the adsorption on chitin [21], chitosan [21,27,28], and Neem sawdust [29], was further improved by the ability of metal ions to penetrate into the internal structure of chitosan.

Figure 2 also confirms that the adsorption process was rather rapid, with $t_{1 / 2}<18 \mathrm{~min}$ and the maximum adsorption obtained in about $120 \mathrm{~min}$. The reference time for the subsequent equilibrium tests was thus set at $120 \mathrm{~min}$, an adequate compromise between accuracy and speed in the execution of experimental tests.

\subsection{Effect of $p H$}

Figure 3 shows the effect of $\mathrm{pH}$ on $\mathrm{Cr}(\mathrm{III})$ adsorption on chitosan. Notably, the $\mathrm{pH}$ of the solution strongly affected the adsorption of metal ions, with the latter increasing with the $\mathrm{pH}$ of the solution. Under acidic conditions, the amino groups $\left(\mathrm{R}_{-} \mathrm{NH}_{3}{ }^{+}\right)$and the hydroxyl groups $\left(\mathrm{R}_{-} \mathrm{OH}_{2}{ }^{+}\right)$are protonated and the molecule is a sort of polycation, with a reduced number of binding sites available for the adsorption of $\mathrm{Cr}(\mathrm{III})$; according to [30], the pKa of the amine groups is 6.3. In addition, the positive surface charge may hinder the adsorption of metal ions. On the contrary, a high $\mathrm{pH}$ will favor their adsorption since the nitrogen free electron doublet is responsible for cations coordination. Considering that $\mathrm{K}_{\mathrm{ps}}=\left[\mathrm{Cr}^{3+}\right] \times[\mathrm{OH}]^{3}=6.7 \times 10^{-31}$, chromium(III) hydroxide begins to precipitate at $\mathrm{pH} \approx 6.5$; for $\mathrm{pH}$ values higher than 3.8 , there is a significant reduction of the $\mathrm{Cr}$ (III) fraction, with formation of $\mathrm{Cr}(\mathrm{OH})^{2+}$ and $\mathrm{Cr}(\mathrm{OH})_{2}{ }^{+}$hydrolyzed complex species [20]. The result is an increase in chromium adsorption due mainly to hydrolyzed forms. Therefore, the adsorption of metal ions is mainly due to the electrostatic interactions between counter ions.

As previously reported [21], the final $\mathrm{pH}$ values of the equilibrated solutions were higher as the $\mathrm{Cr}(\mathrm{III})$ concentration became smaller (Table 2). This is probably due to the fact that $\mathrm{Cr}$ ions are Lewis acids; therefore, the lower the concentration, the higher the $\mathrm{pH}$ (Figure 3). Moreover, the chromium adsorption capacity increases by increasing the metal ions concentration (see Section 3.4), which causes a greater competition with $\mathrm{H}^{+}$protons. 


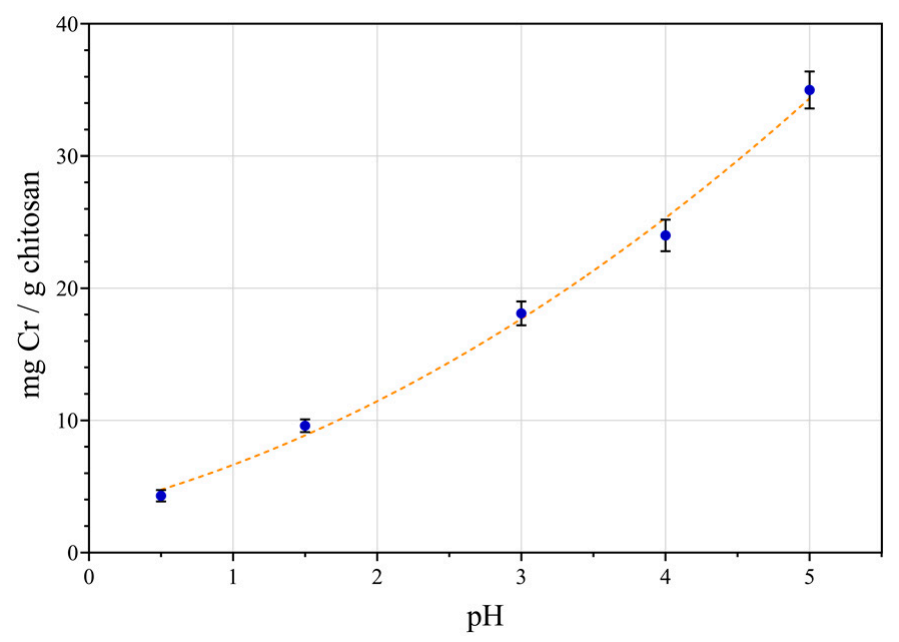

Figure 3. Effect of $\mathrm{pH}$ (initial value) on chromium(III) adsorption on chitosan $\left(\mathrm{C}_{0}=500 \mathrm{mg} \mathrm{L}^{-1}\right)$.

Table 2. $\mathrm{pH}$ variation vs. $\mathrm{Cr}(\mathrm{III})$ concentration $\left(\mathrm{pH}_{\mathrm{in}}=3.8\right)$.

\begin{tabular}{cc}
\hline Cr(III) (ppm) & $\mathbf{p H}$ \\
\hline 50 & 5.16 \\
100 & 5.02 \\
200 & 4.98 \\
400 & 4.67 \\
500 & 4.47 \\
\hline
\end{tabular}

As already stated, it is accepted that chitosan amino groups are the main reactive sites for metal ions and that hydroxyl groups (in particular in C-3 position) may contribute to sorption. Metal sorption may involve different mechanisms (chelating, electrostatic attraction) depending on the $\mathrm{pH}$, the solution, and the metal (concentration, speciation, etc.). Protonation of the amino groups at acidic $\mathrm{pH}$ increases the adsorption of anionic species, while cations interactions increase with the $\mathrm{pH}$ due to deprotonation of amino/hydroxyl groups. Moreover, increasing the ions competition, due to increase in metal concentration, the $\mathrm{pH}$ decreases. The fraction of free (accessible) amine groups is the key parameter.

\subsection{Adsorption Isotherms}

To determine the maximum adsorption capacity of $\mathrm{Cr}$ (III) on chitosan, a study was carried out on the adsorption isotherm by comparing the most common models; in particular, data were analyzed using the Langmuir and Freundlich equations:

$$
\begin{gathered}
q_{e}=Q^{\circ} k_{L} C_{e q} /\left(1+k_{L} C_{e q}\right) \quad \text { or, linearized } 1 / q_{e}=1 /\left(Q^{\circ} k_{L}\right)\left(1 / C_{e q}\right)+1 / Q^{\circ} \\
q_{e}=k_{F} C_{e q}^{1 / n} \text { or, linearized } \log \left(q_{e}\right)=\log \left(k_{F}\right)+1 / n \log \left(C_{e q}\right)
\end{gathered}
$$

where $q_{e}\left(\mathrm{mg} \mathrm{g}^{-1}\right)$ is the amount of $\mathrm{Cr}(\mathrm{III})$ on the solid phase at equilibrium, and $C_{e q}\left(\mathrm{mg} \mathrm{L}^{-1}\right)$ is the equilibrium concentration of $\mathrm{Cr}(\mathrm{III})$ in the aqueous phase. According to Langmuir's equation, $Q^{\circ}\left(\mathrm{mg} \mathrm{g}^{-1}\right)$ is the amount of $\mathrm{Cr}(\mathrm{III})$ required for a complete coverage of available adsorption sites, while $k_{L}$ is an empirical coefficient related to the affinity of adsorption sites for the adsorbed species. With reference to Freundlich's equation, $k_{F}$ and $n$ are empirical constants representing the adsorption capacity and adsorption intensity, respectively; all parameters can be estimated through the intercepts and slopes of the linearized forms of isotherm equations. 
The essential characteristics of the Langmuir equation can be expressed in terms of a dimensionless separation factor $R_{L}$, which has been defined in [27] as:

$$
R_{L}=1 /\left[1+\left(k_{L} C_{o}\right)\right]
$$

where $C_{o}$ is the highest initial $\mathrm{Cr}(\mathrm{III})$ ion concentration $\left(\mathrm{mg} \mathrm{L}^{-1}\right) . R_{L}$ is related to the shape of the isotherm: the adsorption is unfavorable if $R_{L}>1$, favorable if $0<R_{L}<1$, irreversible if $R_{L}=0$, and linear if $R_{L}=1$. All the estimated isotherm parameters are reported in Table 3. The $R_{L}$ value confirms the affinity between chitosan and chromium ions, and the adsorption equilibrium data correlate well with the Langmuir isotherm equation, with a maximum adsorption capacity estimated at $138.04 \mathrm{mg} \mathrm{g}^{-1}$. This implies a monolayer interaction of chromium on the adsorbent [31]. Ngah and colleagues [23] found that $Q^{\circ}$ was $30.03 \mathrm{mg} \mathrm{g}^{-1}$ using $\mathrm{Cr}(\mathrm{III})$ in the range $4-14 \mathrm{mg} \mathrm{L}^{-1}$ and identified the Langmuir isotherm as the best model for the adsorption on cross-linked chitosan. However, the chromium concentrations considered were much lower than those investigated in the present work, and the number of amino groups available for ions coordination in cross-linked chitosan is limited, which obviously results in a lower adsorption capacity. Eiden and colleagues [32] found that $Q^{\circ}$ was $62 \mathrm{mg} \mathrm{g}^{-1}$ for chitosan flakes at $\mathrm{pH}=4$, but no information regarding chitosan characteristics was provided (especially regarding its degree of deacetylation).

Table 3. Langmuir's and Freundlich's isotherm parameters at $20^{\circ} \mathrm{C}, \mathrm{C}_{0}=0.5 \mathrm{~g} \mathrm{~L}^{-1}$, and $\mathrm{pH}=3.8$.

\begin{tabular}{ccccccc}
\hline & Langmuir & \multicolumn{3}{c}{ Freundlich } \\
\hline $\mathbf{Q}^{\circ}\left(\mathbf{m g ~ g}^{-\mathbf{1}}\right)$ & $k_{\mathbf{L}}$ & $\mathbf{R}^{\mathbf{2}}$ & $\boldsymbol{R}_{\boldsymbol{L}}$ & $\boldsymbol{k}_{\boldsymbol{F}}\left(\mathbf{m g ~ g}^{\mathbf{- 1}}\right)$ & $\mathbf{1} / \boldsymbol{n}$ & $\mathbf{R}^{\mathbf{2}}$ \\
\hline 138.04 & $3.7 \times 10^{-4}$ & 0.9925 & 0.575 & 0.035 & 1.061 & 0.9694 \\
\hline
\end{tabular}

Indeed, the basis of the high adsorption capacity found in our study lies precisely in the fact that the investigated chromium concentrations are much higher than those reported in other works (see Figure 2, which shows that adsorption on chitosan increases with the concentration of the target species). Although the different experimental conditions make it difficult to compare the results obtained, it can be observed that at lower concentrations, the adsorption is in line with the values found in the literature (Figures 2 and 4).

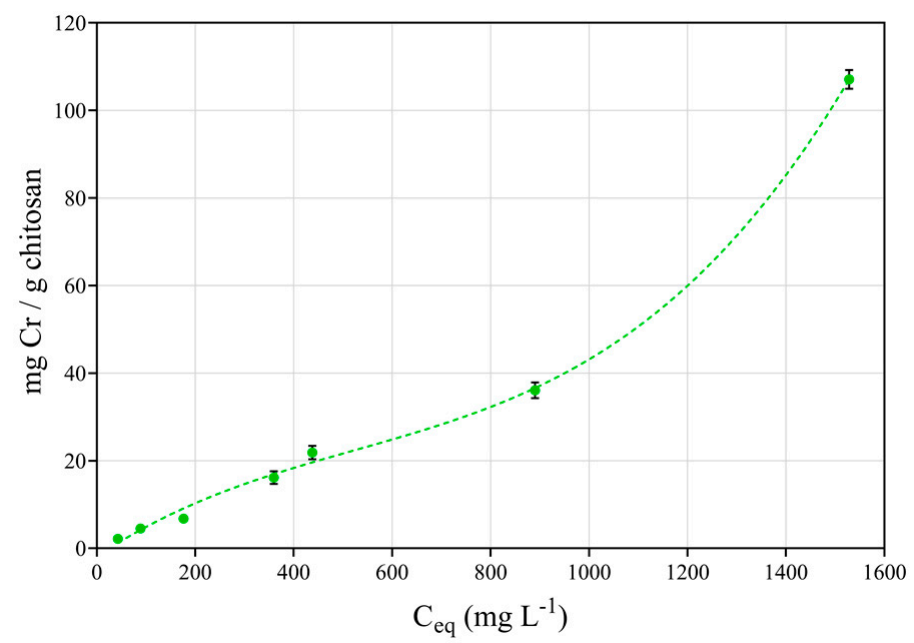

Figure 4. Adsorption isotherm at $20^{\circ} \mathrm{C}, \mathrm{C}_{0}=50-2000 \mathrm{mg} \mathrm{L}^{-1}$, and $\mathrm{pH}=3.8$.

\subsection{Desorption}

After $\mathrm{Cr}(\mathrm{III})$ adsorption, the chitosan flakes were washed thoroughly with deionized water and treated with the desorption agents. Desorption tests were performed using $\mathrm{H}_{2} \mathrm{SO}_{4}$ and EDTA as 
desorption reagents; the chromium desorption efficiency of chitosan flakes for different washing solutions is reported in Table 4.

Table 4. Desorption efficiency (\%) for each adsorption cycle.

\begin{tabular}{cccccc}
\hline Reagent & 1st Cycle & 2nd Cycle & 3rd Cycle & 4th Cycle & 5th Cycle \\
\hline EDTA 0.05 M & 53.3 & - & - & - & - \\
EDTA 0.1 M & 76.5 & 73.4 & 70.6 & 71.7 & 72.1 \\
$\mathrm{H}_{2} \mathrm{SO}_{4} 0.05 \mathrm{M}$ & 37.8 & - & - & - & - \\
$\mathrm{H}_{2} \mathrm{SO}_{4} 0.1 \mathrm{M}$ & 45.3 & 46.5 & 40.7 & 43.1 & 39.7 \\
\hline
\end{tabular}

As reported in [23], EDTA is an efficient desorption agent: being an hexadentate chelating agent, it is capable to form a strong complex with $\mathrm{Cr}$ (III) ions. Considering the $\mathrm{pH}$ effect on the chromium adsorption, sulfuric acid (such as other acidic media) was also considered as a reagent potentially able to remove $\mathrm{Cr}$ (III) ions from the chitosan polymer.

Despite being efficient in terms of chitosan regeneration, EDTA persists in municipal wastewater treatments, making its use in technical applications potentially unwelcome. Although future research may investigate other chelating agents that are biodegradable and more suitable for wastewater treatment plants, the current approach has considered the possibility of treating the spent solution to recover EDTA by precipitation in acidic media as a precautionary measure.

\subsection{Dynamic Tests}

The effect of competing ions can be observed from the breakthrough curves shown in Figure 5. The inhibition effect of anions such as chlorides and sulfates has been reported for $\mathrm{Cr}(\mathrm{VI})$ [33]; in addition, it has been reported that chitosan forms complexes with transition metal ions, but not with complexes with alkali and alkali earth metal ions due to the absence of $d$ and $f$ unsaturated orbitals [34,35]. Therefore, the presence of $\mathrm{Na}, \mathrm{Mg}$, and $\mathrm{Ca}$ does not reduce the chromium adsorption. In contrast, the removal of chromium is influenced by the presence of zinc and cadmium due to their affinity with chitosan [36]. When real wastewater was considered, chitosan was able to absorb $104.7 \mathrm{mg} \mathrm{g}^{-1}$ of chromium, while $127.5 \mathrm{mg} \mathrm{g}^{-1}$ were adsorbed using a chromium solution.

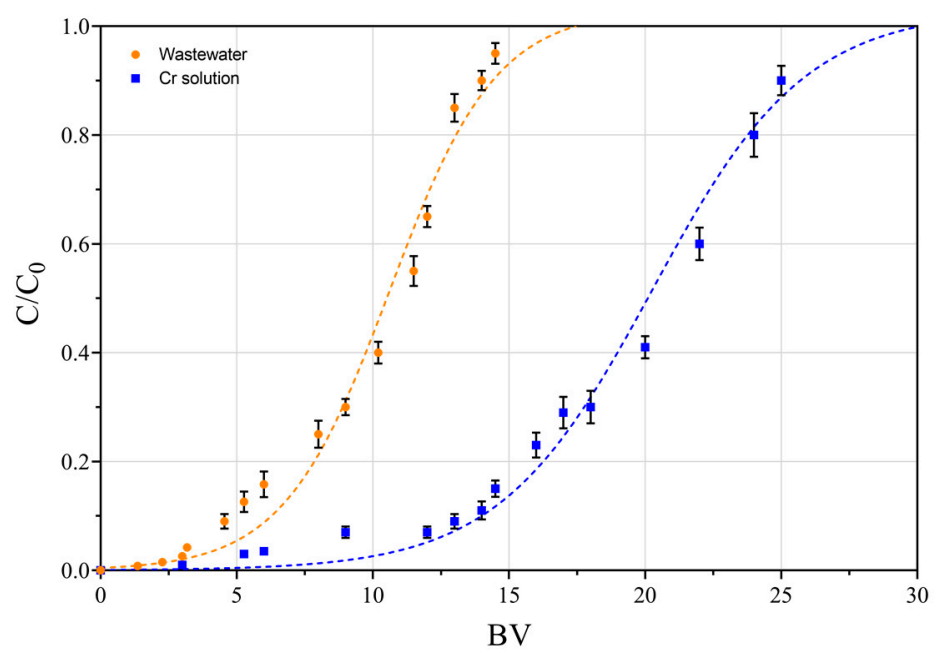

Figure 5. Breakthrough tests performed with real wastewater solution $(\mathrm{pH}=3.2)$ and $500 \mathrm{mg} \mathrm{L}^{-1}$ chromium(III) solution (at $\mathrm{pH}=3.5)$, using a flow rate of $1 \mathrm{BV} \mathrm{h}^{-1}(\mathrm{BV}=23.6 \mathrm{~mL})$.

The breakthrough curve should be symmetrical and sigmoid in shape; however, a deviation from a symmetrical S-shape and not very steep curves can be observed in Figure 5. The packed column was probably not very homogeneous (chitosan flakes seem to be inappropriate to be used in a packed 
column) and the flow-rate was too fast, causing physical non-equilibrium processes and high mass transfer zone [37].

\section{Conclusions}

The present study indicated the suitability of chitosan in applications aimed at removing chromium(III) ions from aqueous solutions. Chitosan is a low-cost reagent and its utilization is novel, non-toxic, and environmentally compatible. Although its effectiveness has been proven in the adsorption of several metal ions, such as $\mathrm{Cu}, \mathrm{Ag}, \mathrm{Cd}, \mathrm{Zn}, \mathrm{Mo}, \mathrm{V}, \mathrm{Pb}$, and $\mathrm{Cr}(\mathrm{VI}), \mathrm{Cr}(\mathrm{III})$ has been poorly investigated. Moreover, among the usable forms of chitosan, flakes are the least studied. In this work, the adsorption of $\mathrm{Cr}$ (III) on chitosan flakes was investigated considering concentrations (up to $2000 \mathrm{mg} \mathrm{L}^{-1}$ ) that are much higher than those reported in the few studies present in literature. This made it possible to highlight a much higher adsorption capacity of chitosan (up to $138.45 \mathrm{mg} \mathrm{g}^{-1}$ ), well beyond the values observed so far.

The $\mathrm{pH}$ significantly influences the adsorption capacity of the biopolymer, the latter increasing with the $\mathrm{pH}$ of the solution. The adsorption process is rather rapid: it was found that $2 \mathrm{~h}$ of contact time are sufficient to reach about $95 \%$ of the adsorption equilibrium; the Langmuir equation provided the best fit over the entire concentration range, thus suggesting a monolayer interaction of chromium on the adsorbent.

The adsorption capacity for $\mathrm{Cr}(\mathrm{III})$ in dynamic tests was found to be penalized by the competition between ions, and particularly influenced by the presence of zinc and cadmium due to their strong affinity with chitosan. The recovery of $\mathrm{Cr}$ (III) ions (and the consequent regeneration of chitosan) can be obtained by desorption with a 0.1 M EDTA solution, with the latter being recoverable by precipitation in an acidic medium.

Since chitosan is basically a low-cost and environmentally friendly material, its use as it is produced (i.e., flakes) is desirable, especially considering the greater theoretical adsorbent capacity due to a major availability of both amino and hydroxyl groups, but involves some critical issues. In particular, since the shape and size characteristics of commercial chitosan flakes introduce hydrodynamic limitations such as column clogging, a batch reactor is probably more appropriate as a experimental setup. Further investigations are therefore underway to quantify the effectiveness of alternative operating solutions.

Author Contributions: Conceptualization, L.P.; methodology, L.P. and A.P.; validation, L.P. and I.F.; investigation, I.S. and M.S.; data curation, M.V.; writing-original draft preparation, L.P. and M.V.; writing-review and editing, L.P. and M.V.; project administration, L.P.; funding acquisition, L.P. All authors have read and agree to the published version of the manuscript.

Funding: This research received no external funding.

Conflicts of Interest: The authors declare no conflict of interest.

\section{References}

1. Pietrelli, L.; Ippolito, N.M.; Reverberi, A.P.; Vocciante, M. Heavy Metals Removal and Recovery from Hazardous Leather Sludge. Chem. Eng. Trans. 2019, 76, 1327-1332.

2. Rengaraj, S.; Yeon, K.H.; Moon, S.H. Removal of chromium from water and wastewater by ion exchange resins. J. Hazard. Mater. 2001, 87, 273-287. [CrossRef]

3. Vocciante, M.; Reverberi, A.P.; Pietrelli, L.; Dovì, V.G. Improved remediation processes through cost-effective estimation of soil properties from surface measurements. J. Clean. Prod. 2017, 167, 680-686. [CrossRef]

4. Vocciante, M.; Finocchi, A.; De Folly, D.; Auris, A.; Conte, A.; Tonziello, J.; Pola, A.; Reverberi, A.P. Enhanced Oil Spill Remediation by Adsorption with Interlinked Multilayered Graphene. Materials 2019, $12,2231$. [CrossRef] [PubMed]

5. Fu, F.; Wang, Q. Removal of heavy metal ions from wastewaters: A review. J. Environ. Manag. 2011, 92, 407-418. [CrossRef] [PubMed] 
6. Vocciante, M.; De Folly, D.; Auris, A.; Finocchi, A.; Tagliabue, M.; Bellettato, M.; Ferrucci, A.; Reverberi, A.P.; Ferro, S. Adsorption of ammonium on clinoptilolite in presence of competing cations: Investigation on groundwater remediation. J. Clean. Prod. 2018, 198, 480-487. [CrossRef]

7. El-Shafey, E.I.; Cox, M.; Pichugin, A.A.; Appleton, Q. Application of a carbon sorbent for the removal of cadmium and other heavy metal ions from aqueous solution. J. Chem. Technol. Biotechnol. Intern. Res. Process Environ. Clean Technol. 2002, 77, 429-436. [CrossRef]

8. Garcia-Reyes, R.B.; Rangel-Mendez, J.R. Adsorption kinetics of chromium (III) ions on agro-waste materials. Bioresour. Technol. 2010, 101, 8099-8108. [CrossRef] [PubMed]

9. Chen, L.F.; Liang, H.W.; Lu, Y.; Cui, C.H.; Yu, S.H. Synthesis of an attapulgite clay@ carbon nanocomposite adsorbent by a hydrothermal carbonization process and their application in the removal of toxic metal ions from water. Langmuir 2011, 27, 8998-9004. [CrossRef]

10. Pietrelli, L.; Ippolito, N.M.; Ferro, S.; Dovì, V.G.; Vocciante, M. Removal of Mn and As from drinking water by red mud and pyrolusite. J. Environ. Manag. 2019, 237, 526-533. [CrossRef]

11. Pietrelli, L.; Ferro, S.; Vocciante, M. Raw materials recovery from spent hydrochloric acid-based galvanizing wastewater. Chem. Eng. J. 2018, 341, 539-546. [CrossRef]

12. Chiou, M.S.; Li, H.Y. Adsorption behavior of reactive dye in aqueous solution on chemical cross-linked chitosan beads. Chemosphere 2003, 50, 1095-1105. [CrossRef]

13. Pietrelli, L.; Xingrong, L. Chitosan membrane: Tool for chromium (III) recovery from aqueous solutions. Ann. Chim. J. Anal. Environ. Cult. Herit. Chem. 2004, 94, 389-398. [CrossRef] [PubMed]

14. Ko, J.A.; Kim, B.K.; Park, H.J. Preparation of acetylated chitosan sponges (chitin sponges). J. Appl. Polym. Sci. 2010, 117, 1618-1623. [CrossRef]

15. Guibal, E. Interactions of metal ions with chitosan-based sorbents: A review. Sep. Purif. Technol. 2004, 38, 43-74. [CrossRef]

16. Bakshia, P.S.; Selvakumara, D.; Kadirvelub, K.; Kumara, N.S. Chitosan as an Environment Friendly Biomaterial-A Review on Recent Modifications and Applications. Int. J. Biol. Macromol. 2019, in press. [CrossRef] [PubMed]

17. Wei, S.; Ching, Y.C.; Chuah, C.H. Synthesis of chitosan aerogels as promising carriers for drug delivery: A review. Carbohydr. Polym. 2019, 231, 115744. [CrossRef]

18. Mujtaba, M.; Morsi, R.E.; Kerch, G.; Elsabee, M.Z.; Kaya, M.; Labidi, J.; Khawar, K.M. Current advancements in chitosan-based film production for food technology: A review. Int. J. Biol. Macromol. 2019, 121, 889-904. [CrossRef]

19. Vakili, M.; Deng, S.; Cagnetta, G.; Wang, W.; Meng, P.; Liu, D.; Yu, G. Regeneration of chitosan-based adsorbents used in heavy metal adsorption: A review. Sep. Purif. Technol. 2019, 224, 373-387. [CrossRef]

20. Fendorf, S.E. Surface reactions of chromium in soils and waters. Geoderma 1995, 67, 55-71. [CrossRef]

21. Maruca, R.; Suder, B.J.; Wightman, J.P. Interaction of heavy metals with chitin and chitosan. III. Chromium. J. Appl. Polym. Sci. 1982, 27, 4827-4837. [CrossRef]

22. Chui, V.W.D.; Mok, K.W.; Ng, C.Y.; Luong, B.P.; Ma, K.K. Removal and recovery of copper (II), chromium (III), and nickel (II) from solutions using crude shrimp chitin packed in small columns. Environ. Int. 1996, 22, 463-468. [CrossRef]

23. Ngah, W.W.; Kamari, A.; Fatinathan, S.; Ng, P.W. Adsorption of chromium from aqueous solution using chitosan beads. Adsorption 2006, 12, 249-257. [CrossRef]

24. Lerivrey, J.; Dubois, B.; Decock, P.; Micera, G.; Urbanska, J.; Kozłowski, H. Formation of D-glucosamine complexes with Cu (II), Ni (II) and Co (II) ions. Inorg. Chim. Acta 1986, 125, 187-190. [CrossRef]

25. Lagergren, S. Zur theorie der sogenannten adsorption geloster stoffe. Kungliga Svenska Vetenskapsakademiens Handlingar 1898, 24, 1-39.

26. Weber, W.J.; Morris, J.L. Kinetics of adsorption on carbon from solutions. J. Sanit. Eng. Div. Proc. Am. Soc. Civ. Eng. 1963, 89, 31-60.

27. McKay, G. Adsorption of dyestuffs from aqueous solutions with activated carbon I: Equilibrium and batch contact-time studies. J. Chem. Technol. Biotechnol. 1982, 32, 759-772. [CrossRef]

28. Annadurai, G.; Ling, L.Y.; Lee, J.F. Adsorption of reactive dye from an aqueous solution by chitosan: Isotherm, kinetic and thermodynamic analysis. J. Hazard. Mater. 2008, 152, 337-346. [CrossRef]

29. Annadurai, G.; Chellapandian, M.; Krishnan, M.R.V. Adsorption of reactive dye on chitin. Environ. Monit. Assess. 1999, 59, 111-119. [CrossRef] 
30. Udaybhaskar, P.; Iyengar, L.; Rao, A.P. Hexavalent chromium interaction with chitosan. J. Appl. Polym. Sci. 1990, 39, 739-747. [CrossRef]

31. Singh, P.; Nagendran, R. A comparative study of sorption of chromium (III) onto chitin and chitosan. Appl. Water Sci. 2016, 6, 199-204. [CrossRef]

32. Eiden, C.A.; Jewell, C.A.; Wightman, J.P. Interaction of lead and chromium with chitin and chitosan. J. Appl. Polymer Sci. 1980, 25, 1587-1599. [CrossRef]

33. Boddu, V.M.; Abburi, K.; Talbott, J.L.; Smith, E.D. Removal of hexavalent chromium from wastewater using a new composite chitosan biosorbent. Environ. Sci. Technol. 2003, 37, 4449-4456. [CrossRef] [PubMed]

34. Hsien, T.Y.; Rorrer, G.L. Effects of acylation and crosslinking on the material properties and cadmium ion adsorption capacity of porous chitosan beads. Sep. Sci. Technol. 1995, 30, 2455-2475. [CrossRef]

35. Kubota, N.; Kikuchi, Y. Macromolecular complexes of chitosan. In Polysccharides; Dumitriu, S., Ed.; Dekker: New York, NY, USA, 1998; pp. 595-628.

36. Bassi, R.; Prasher, O.; Simpson, B.K. Removal of selected metal ions from aqueous solutions using chitosan flakes. Sep. Sci. Technol. 2000, 35, 547-560. [CrossRef]

37. Patel, H. Fixed-bed column adsorption study: A comprehensive review. Appl. Water Sci. 2019, 9, 45. [CrossRef]

(C) 2020 by the authors. Licensee MDPI, Basel, Switzerland. This article is an open access article distributed under the terms and conditions of the Creative Commons Attribution (CC BY) license (http://creativecommons.org/licenses/by/4.0/). 